University of Nebraska - Lincoln

DigitalCommons@University of Nebraska - Lincoln

September 1988

\title{
Scanning electron microscope identification of weak links in superconducting thin films
}

Don Monroe

AT\&T Bell Laboratories, Murray Hill, New Jersey

W.S. Brocklesby

AT\&T Bell Laboratories, Murray Hill, New Jersey

R.C. Farrow

AT\&T Bell Laboratories, Murray Hill, New Jersey

M. Hong

AT\&T Bell Laboratories, Murray Hill, New Jersey

Sy_Hwang Liou

University of Nebraska-Lincoln, sliou@unl.edu

Follow this and additional works at: https://digitalcommons.unl.edu/physicsliou

Part of the Physics Commons

Monroe, Don; Brocklesby, W.S. ; Farrow, R.C.; Hong, M.; and Liou, Sy_Hwang, "Scanning electron microscope identification of weak links in superconducting thin films" (1988). Si-Hwang Liou Publications. 31.

https://digitalcommons.unl.edu/physicsliou/31

This Article is brought to you for free and open access by the Research Papers in Physics and Astronomy at DigitalCommons@University of Nebraska - Lincoln. It has been accepted for inclusion in Si-Hwang Liou Publications by an authorized administrator of DigitalCommons@University of Nebraska - Lincoln. 


\title{
Scanning electron microscope identification of weak links in superconducting thin films
}

\author{
Don Monroe, W. S. Brocklesby, R. C. Farrow, M. Hong, and S. H. Liou \\ AT\&T Bell Laboratories, Murray Hill, New Jersey 07974
}

(Received 31 May 1988; accepted for publication 26 July 1988)

We have used a pulsed electron beam in a scanning electron microscope to produce highiy localized $(\sim 1 \mu \mathrm{m})$ changes in the electrical properties of a heterogeneous thin fim of $\mathrm{YBa}_{2} \mathrm{Cu}_{3} \mathrm{O}_{7}-8$. The predominant effect of the beam is to locally heat the film, producing a measurable shift in the current-voltage characteristic. In particular, we have precisely located the part of the film responsible for a sharp feature in the current-voltage characteristic corresponding to a single Josephson junction. The technique should also be useful more generally in identifying specific weak links in superconducting thin films.

The exploration of the new oxide superconductors has been complicated by the variety of morphologies in both bulk and thin-film material. Although the availability of single crystals has allowed major advances in understanding the basic physics, for most practical applications a detailed understanding of the influence of material morphology on superconducting properties is essential. For example, although defects and grain boundaries are believed to be inportant in determining the critical current density, the precise role of such microstructure has remained a subject of speculation.

In this letter we describe a technique that directly relates features in the electrical characteristics to particular morphological features, using the beam of a scanning electron microscope (SEM) to modulate the electrical properties of a thin film. This technique has been used previously for a variety of experiments in homogeneous superconductors (see references in Ref. 1); its use as a materials characterization tool for high $T_{c}$ superconductors was recently proposed, and soon afterwards it was used ${ }^{2}$ to map critical currents. In this work we use the technique to locate intrinsic junctions or other types of weak links inherently present in an inhomogeneous film. Our film had an unusual morphology, and we have previously observed ${ }^{3}$ many distinct features in the current-voltage $(I-V)$ characteristic, associated with individual Josephson junctions or small groups of junctions. Using the SEM, we have unambiguously located the position associated with a particular feature. We will briefly discuss factors limiting the achicvable resolution, which is at least $? \mu \mathrm{m}$.

The sample was grown by sputtering from a $\mathrm{YBa}_{2} \mathrm{Cu}_{3} \mathrm{O}_{7}$ \& target onto a $\mathrm{SrTiO}_{3}$ substrate, ${ }^{4}$ and was annealed for $\sim 5 \mathrm{~min}$ at $1045^{\circ} \mathrm{C}$. The morphology consisted of large, rectangular, $c$-axis-perpendicular plateiets of typical size $200 \times 50 \mu \mathrm{m}$, covering $\sim 20-30 \%$ of the surface. The rest of the film contains both $\mathrm{YBa}_{2} \mathrm{Cl}_{3} \mathrm{O}_{7}$ and various nonsuperconducting oxides. Energy dispersive $\mathrm{x}$-ray analysis showed that the piatelets contain significant amounts of strontium diffused in from the substrate. The interesting platelet morphology was limited to a region of about $1 \mathrm{~mm}^{2}$, and contacts and scratches were made to isolate a $500-\mu \mathrm{m}$-wide part of this region electrically. An example of the structure in the isolated region is shown in the secondary electron micrograph in Fig. 1(a). The arrow shows the position associated with a particular electrical feature as discussed below.
The resistance of the sample shows a semiconductorlike increase from room temperature down to the onset of superconductivity at $\sim 70 \mathrm{~K}$. Below $\sim 40 \mathrm{~K}$, at which the sample attains zero resistance, the $I-V$ characteristics show over 30 discrete features corresponding to the switching of a single Josephson junction, or perhaps a few junctions that switch together. Some of these features show hysteresis on current cycling, as illustrated in Fig. 2. The feature whose location we determined using the SEM had a similar, hysteretic $I-V$ characteristic. In general, however, this technique will pinpoint any areas that are more sensitive to ternperature than their surroundings.

The critical currents at which the various features occur decrease rapidly with increasing temperature above $20 \mathrm{~K} .{ }^{3}$ (Here we use the phrase "critical current" as a shorthand for the bias current at which the feature occurs. The true junction critical current is lower, since only a fraction of the bias current passes through the junction.) Thus if the sample is current biased just below the critical current of a particular feature, local heating caused by a nearby electron beam can reduce its critical current, causing it to switch and inducing

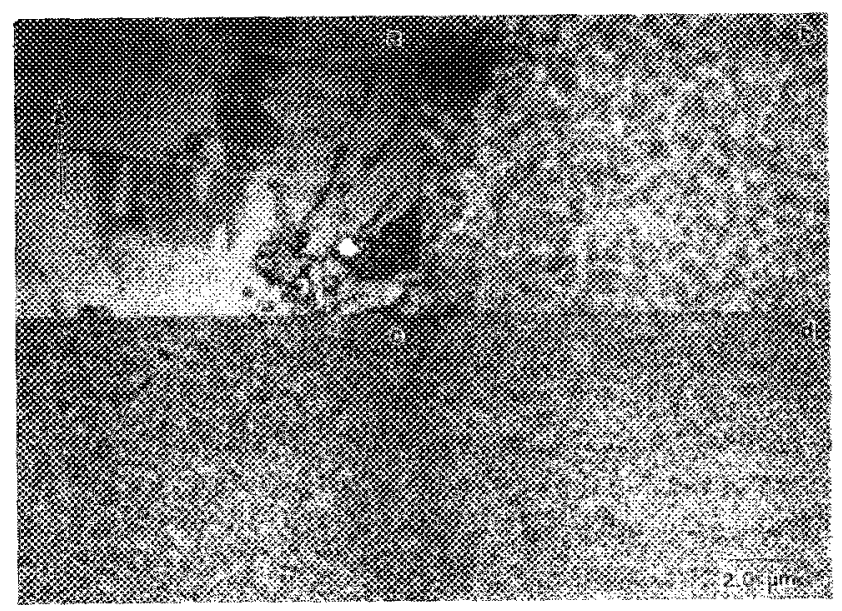

FIO. 1. (a) Secondary electron image of platelet where weak link was located. Arrow shows approximate position of spot in (c). (b) Induced-voltage image taken during initial exploration, using a $20 \mathrm{AA}$ beam current and a $128 \times 100$ matrix. Temperature was $20-30 \mathrm{~K}$. (c) Tiner scale induced-voltage image using $2 \mathrm{nA}$ beam current and a $256 \times 200$ matrix. Sample position was manually shifted, so that the position of the dark spot shown by the arrow is near the center of the dark region of (b). Hias current was 0.542 $m A(d)$ Image taken immediately after and using same conditions as (c), except that the bias current $100.563 \mathrm{~mA}$, just above the feature in the $Z-F$ characteristic as observed simultaneously on an oscilloscope. 


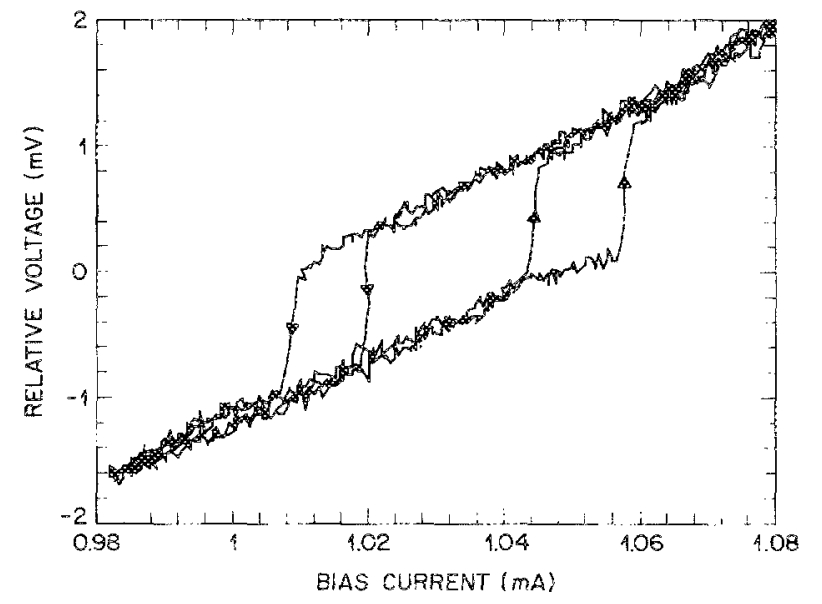

FIG. 2. Portion of the $T-V$ characteristic for a particular electrical feature. A similar, hysteretic feature was located using the electron beam induced voltage image. Temperature was $4.2 \mathrm{~K}$, substantially colder than the $20-30 \mathrm{~K}$ used for the images in Fig. 1 .

an extra voltage across the sample. By chopping the electron beam (at $10 \mathrm{kHz}$ ) and detecting the modulated part of the voltage as the electron beam is scanned, we get a map of the local sensitivity to heating at a particular bias current. Figures $1(b)-1$ (d) show such maps, with darker regions representing a larger voltage modulation by the electron beam. The experiments were performed in a modified ISI SS60 SEM. The micrographs of the electron beam induced voltage [Figs. 1(b)-1(d)] were recorded and processed with an EDAX 9900 image processor.

A detailed discussion of the resolution of this technique has been given by Clem and Huebener." Any technique based on heating can resolve nothing smaller the size of the roughy spherical region in which the electron energy is in:tially deposited. ${ }^{1}$ The diameter of this region can be estimated by Monte Carlo simulation ${ }^{7}$ to be $\sim 1 \mathrm{\mu m}$ for $12 \mathrm{keV}$ electrons. Further degradation of resolution can be caused by thermal diffusion, especially at very low temperatures where thermal boundary resistance between the film and the substrate can trap heat in the flm. However, since the acoustic mismatch boundary resistance is theoretically proportional to $T^{3}$, at the temperature of these experiments we estimate the themal healing Jength ${ }^{6}$ over which the heat spreads before leaking into the substrate to be comparable to the film thickness. A more appropriate model is therefore diffusion into a semi-infinite substrate, for which the temperature change is inversely proportional to the distance from the source.

The resolution is also strongly affected by the nonlinear response of the fim to temperature. The junction will only switch if the local temperature rise reduces the critical current below the current flowing through the junction. Thus, by biasing the sample just below the critical current and using a small electron beam current, the resolution of the technique may approach the size of the heating source, as illustrated in Fig. 1(c). Figure 1 (d) shows a voltage image of the same region with the same beam current, but biased slightly above rather than slightly below the critical current for this junction. The disappearance of the spot with either a small increase or (not shown) decrease in bias proves the direct connection between the dark region in the voltage image and the feature in the $I-V$ characteristic. This observation is in contrast with those of Gross et $a l .,{ }^{2}$ in which features present at low biases appeared to persist to higher biases, and may indicate that different mechanisms are involved in the two cases.

A simple calculation shows that the heating caused by the electron beam is adequate to cause the observed effects. For heat fow into a semi-infinite region from a circular heat source of radius $a$, the steady-state temperature rise at the center of the circle is $P /(\pi a n)$, where $P$ is the total power and $K$ is the thermal conductivity. To estimate the temperature rise, we assume that the thermal conductivity of the $\mathrm{SrTiO}_{3}$ substrate and of the $\mathrm{YBa}_{2} \mathrm{Cu}_{3} \mathrm{O}_{7}-8$ flm are similar, and are about $0.1 \mathrm{~W} \mathrm{~cm}^{-1} \mathrm{~K}^{-1} \cdot$. For an electron energy of $12 \mathrm{keV}$, a current of $2 \mathrm{nA}$ [corresponding to Fig. 1(c)], and a source diameter $2 a$ of $\mathrm{l} \mu \mathrm{m}$, we estimate a temperature rise of $1.5 \mathrm{~K}$. From separate measurements of $d I_{i} / d T \sim-0.05$ $\mathrm{mA} / \mathrm{K}$ for this feature, this temperature rise should reduce the critical current by about $80 \mu \mathrm{A}$, enough to cause the switch from lower to higher voltage state. This steady-state increase is achieved in a response time of order $a^{2} / D$, which for a thermal diffusivity $D$ of $0.15 \mathrm{~cm}^{2} s{ }^{1}$, and a radius $a$ $-0.5 \mu \mathrm{m}$, is less than $20 \mathrm{~ns}$, much faster than the $100 \mu \mathrm{s}$ chopping period. As emphasized by Clem and Huebener, ${ }^{6}$ modulating the electron beam faster than the response time should improve the resolution.

Further evidence that the dark region shows the position of the junction was obtained unintentionaly, by increasing the beam current while the beam was fixed on the spot shown in Fig. 1 (c). Following this intense illumination, the chosen feature in the $I-V$ characteristic disappeared permanently, while other features with comparable critical currents were unchanged! Presumably the energy deposited by the electron beam accumulated to the point of destroying the junction, or at least drastically changing its critical current.

The junction is located in the middle of one platelet, close to but not at a piece of extra material on the surface, and close to a crack in the platelet. This surprising location would not have been guessed in the absence of an objective technique such as the one discussed. Further exploration will be required to determine if this location is typical or pathological.

In summary, we have demonstrated a technique that can relate particular details in the $I-V$ characteristics of a heterogeneous thin film to particular areas of the film. The present study has been conducted on a film with an unusual morphology and a low critical current, in which the presence of identifable structure in the $I$ - $V$ characteristic makes the connection particularly compelling. In addition to the identifcation of junctions as in this letter, and the mapping of critical currents discussed by Gross et al., ${ }^{2}$ other possible uses of this technique include the study of thermally induced vortex motion' ${ }^{3}$ and the identification of higher critical temperature minority phases.

'R. P. Huebener, R. Gross, and J. Bosch, Z. Phys. B 70, 425 (1988) ${ }^{2}$ R. Gross, J. Bosch, R. I. Huebener, J. Mannhart, C. C. Tsuei, M. Scheuer- 
mann, M. M. Oprysko, and C. C. Chi, Nature 332, 818 (1988).

${ }^{3}$ W. S. Brocklesby, Don Monroe, M. Hong, \$. H. Iiou, J. K wo, G. J. Fisanick, P. M. Mankiewich, and R. E. Howard (unpublished).

${ }^{4}$ M. Hong, S. H. Liou, I. Kwo, and B. A. Davidson, Appl. Phys. Lett. 51, 694 (1987).

S. IF. K iou, M. Hong, B. A. Davidson, R. C. Farrow, J. Kwo, T. C. Hsieh, R. M. Fleming, H. S. Chen, L. C. Feldman, A. R. Kortan, and R. J. Felder, in Thin Flm Processing and Characterization of High-temperature Superconductors, edited by I. M. F. Harper, R. J. Colton, and L. C. Feldman, American Institute of Physics Conference Procedings No. 165 (American Irstitute of I'hysics, New York, 1988), p. 79.

${ }^{6} J$ ohn R. Clem and R. P. Huebener, J. Appl. Phys. 51, 2764. (1980).
TSe D. E. Newbury, D. C. Joy, F. Echlin, C. E. Fiori, and J. 1. Goldstein, Aduanced Scanning Electron Microscopy and X-ray Microanalysis (PRenum, New York, 1986), Chap. 1.

H. S. Carslaw and $\$$. C. Jaeger, Conduction of Heat in Solids, 2nd ed. (Clarendon, London, 1959), p. 264, give the complete spatial and temporal dependence for this case.

"This estimate comes from an extrapolation of single-crystal data due to $\mathrm{J}$. F. Graebner, L. F. Schneemeyer, R. J. Cava, J. V. Waszczak, and F. A. Rictman, in High-Temperature Superconductivity, Fall 1987, edited by M. 13. Brodsky, R. C. Dynes, K. Kitazawa, and H. L. Tuller, Materials Research Society Procedings, No. 99 (Materials Research Society, Pittsburgh, 1988 ), p. 745 . 